\title{
Evidences for involvement of endogenous cAMP in Arabidopsis defense responses to Verticillium toxins
}

\author{
Jing JIANG, Ling Wen FAN, Wei Hua WU* \\ The State Key Laboratory of Plant Physiology \& Biochemistry, College of Biological Sciences, China Agricultural University, \\ Beijing 100094, China
}

\begin{abstract}
Although there were reports suggesting the involvement of endogenous cAMP in plant defense signaling cascades, there is no direct evidence supporting this notion yet and the detailed mechanism is unclear. In the present study, we have used pathogenic fungi Verticillium dahliae and Arabidopsis plants as a model system of plant-microb interaction to demonstrate the function of endogenous cAMP in Arabidopsis defense responses. Both $V$. dahliae inoculation and Verticillium toxins injection induced typical "wilt" symptoms in Arabidopsis seedlings. When either 8-Br-AMP (a membrane permeable cAMP analogue) or salicylic acid (SA) was applied to Arabidopsis, the plants became resistant to $V$. dahliae toxins. However, addition of 8-Br-AMP did not increase the resistance of Arabidopsis transgenic plants deficient in SA to the toxins, suggesting that cAMP might act upstream of SA in plant defense signaling pathway. Indeed, 8-Br-cAMP and forskolin, an activator of adenylyl cyclase, significantly stimulated the endogenous SA level in plants, whereas DDA, an inhibitor of adenylyl cyclase dramatically reduced toxin-induced SA increase. Both the endogenous cAMP and SA increased significantly in Arabidopsis seedlings treated with toxins. Furthermore, transcription level of pathogenesis-related protein 1 gene $(P R 1)$ was strongly induced by both 8-Br-cAMP and the toxin treatment. Taken together, our data demonstrate that endogenous cAMP is involved in plant defense responses against Verticilliumsecreted toxins by regulating the production of the known signal SA in plant defense pathway.
\end{abstract}

Keywords: Arabidopsis thaliana, Verticillium dahliae, cyclic AMP, alicylic acid, signal transduction, defense response.

\section{INTRODUCTION}

Verticillium wilt is a soil-borne fungal disease giving serious wilt phenotype for various plant species and resulting in severe loss of crop production [1-3]. Most Verticillium diseases are mainly caused by either Verticillium dahliae or V. albo-atrum [4]. The Verticillium species can produce extracellular toxins that are the cause of most of the symptoms associated with Verticillium wilt disease. The molecular mechanisms involved in plant defense responses to Verticillium are poorly understood. Tomato $V e$ gene, encoding a cell surface-like receptor, is the only known Verticillium-resistance gene, specifically confering plant resistance to $V$. albo-atrum race 1 [5]. Arabidopsis has been used as a model host plant for the analysis of

\footnotetext{
*Correspondence: Wei Hua WU

Tel: +86-10-6273-1103; Fax: +86-10-6273-3491;

E-mail: wuwh@public3.bta.net.cn
}

interaction between Verticillium and the host [6, 7]. Cyclic AMP-mediated signal transduction pathway was found to play a critical role in fungal phytopathogen invasion and growth in the host plants as well as the morphological changes in the hosts (reviewed in [8,9]). However, whether or not the endogenous cAMP in plant cells is involved in plant defense responses remains unknown. During the past decade, the importance of endogenous cAMP function in signal transduction in higher plants including plant defense responses gains more recognition (reviewed in [10-13]). The enzymes involved in cAMP metabolism in higher plants (such as adenylyl cyclase for cAMP synthesis [14]) and cAMP-dependent proteins (such as cAMP-dependent protein kinase A-like kinase (PKA) [15]) as well as cAMP response element-binding proteins (CREBs) [16] were identified and analyzed. A transient increase in amount of cAMP in response to pathogenic elicitors has been demonstrated in French bean [17], carrot [18], Medicago sativa [19] and Cupressus lusitanica [20]. Interestingly, one of the first 
cloned plant disease-resistance gene, the RPS gene, contains leucine-rich repeats, which is also present in yeast adenyl cyclase [21]. Recently, two Arabidopsis lesionmimic mutants $d n d 1$ and $h l m 1$, which show increased disease resistance, were demonstrated as mutants with mutations in genes encoding cyclic nucleotide-gated channels (CNGCs) $[22,23]$, suggesting that disease resistance could be activated in plants by disruption of cyclic nucleotide-gated ion channels. cAMP seems to be a critical signaling molecule in mediating plant defense responses to phytopathogens.

Salicylic acid is the best-characterized signaling molecule in plant defense response (reviewed in [24-27]). Transgenic plants expressing the bacterial NahG gene, which encodes an enzyme that catalyze SA hydrolysis, show reduced or depleted expression of $P R$ genes, and loss of systemic acquired resistance [28]. Phenylalanine ammonia-lyase (PAL) is a key enzyme in SA synthesis and is expressed in response to a variety of pathogens and pathogen-derived elicitors $[29,30]$. Treatment of plant seedlings with membrane-permeable cAMP analogue resulted in the stimulation of phenylalanine ammonia-lyase activity [21], suggesting that cAMP might induce an accumulation of SA in plants.

In this study, we report an improved disease resistance of Arabidopsis plant to $V$. dahliae toxins, induced by exogenous application of either cAMP or SA. The treatment of Arabidopsis plants with $V$. dahliae toxins resulted in increases of either endogenous cAMP or SA contents in plant seedlings. Application of exogenous membrane-permeable cAMP analogue induced rapid increases of SA level and $P R 1$ transcription. In conclusion, endogenous cAMP functions upstream of SA signal in plant defense responses against pathogen Verticillium by regulating SA production and the activation of subsequent plant defense pathway.

\section{MATERIALS AND METHODS}

\section{Plants growth conditions and pathogen inoculation}

Arabidopsis seeds (ecotype Columbia) were grown in mixed sterilized soil in a growth chamber under a $12 \mathrm{~h}$ light/ $12 \mathrm{~h}$ dark cycle $\left(100 \mu \mathrm{mol} / \mathrm{m}^{2} / \mathrm{s}\right)$ and temperatures of $22 \pm 1^{\circ} \mathrm{C}$ and $15 \pm 4^{\circ} \mathrm{C}$ for daylight and night respectively. The relative humidity was kept at approximately $70 \%$. The strain V229 of $V$. dahliae, a nondefoliating and strong pathogenic fungal strain was used throughout this study. The fungi were first grown in the cottonseed medium for 3 weeks, and then the mycelia were collected and ground with sterile water. The conidia were resuspended and diluted to a concentration of $1 \times 10^{7}$ conidia/ml. Four-week-old Arabidopsis seedlings were rootinoculated with $10 \mathrm{ml}$ conidial suspension per pot. Mock-inoculated plants were $10 \mathrm{ml}$ sterile water added as the control.

\section{Preparation of crude toxin}

The fungi were first activated in the potato dextrose agar medium at $25^{\circ} \mathrm{C}$ in dark for $5 \mathrm{~d}$. The fungal mycelia were cultured in Czapek's hydroponic medium [31] in an orbital shaker set at $170 \mathrm{rpm}$ and $25^{\circ} \mathrm{C}$ for $15 \mathrm{~d}$. The culture was centrifuged at $12,000 \mathrm{~g}$ for $20 \mathrm{~min}$ to remove the mycelium, and the supernatant was filtered through 2 layers of filter paper, and the filtrate was lyophilized and stored at $-20^{\circ} \mathrm{C}$. The frozen-dried material, used as the crude toxins, was dissolved in distilled water. The protein content in the isolated crude toxins was determined by the method of Bradford [32] with bovine serum albumin as a standard.

\section{Phenotypic assay of Arabidopsis seedlings in MS medium}

Vernalized Arabidopsis seeds were sterilized and germinated on $1 \times$ MS medium containing $0.8 \%(\mathrm{w} / \mathrm{v})$ agar and $3 \%(\mathrm{w} / \mathrm{v})$ sucrose at $22^{\circ} \mathrm{C}$ under continuous illumination at $60 \mu \mathrm{mol} / \mathrm{m}^{2} / \mathrm{s}$. After cultured in MS medium for $4 \mathrm{~d}$, the seedlings were transferred to MS medium without or with addition of the fungal toxins and other reagents (such as cAMP, SA, etc.) as indicated in the text and the figures. The stock solutions of these reagents were filtered with a microfilter $(\varnothing=0.22 \mu \mathrm{m})$ before added to MS medium. The toxin solutions were filtered with a $0.45 \mu \mathrm{m}$ microporous filtering film and added to the medium before the medium was solidified (when the temperature of medium was around $60^{\circ} \mathrm{C}$ ). The agar plates were vertically placed in a growth chamber with continuous light $\left(100 \mu \mathrm{mol} / \mathrm{m}^{2} / \mathrm{s}\right)$ at $22^{\circ} \mathrm{C}$ for $4 \mathrm{~d}$ before taking photos.

For the test of Arabidopsis hypersensitive to the fungal toxins, 4 fully expanded Arabidopsis leaves were acupunctured with a small plastic syringe and a drop of $2 \mu 1$ toxins was injected to leaves per needle hole. Mock-induced leaves were injected with $2 \mu 1$ sterilized water as the control. The treated plants were maintained in a growth chamber with a cycle of $12 \mathrm{~h}$ of light (approximately $100 \mu \mathrm{mol} / \mathrm{m}^{2} / \mathrm{s}$ ) and $12 \mathrm{~h}$ of dark at $22 \pm 1^{\circ} \mathrm{C}$ and $70 \%$ relative humidity.

\section{Determination of free $\mathrm{SA}$ contents}

Arabidopsis seeds were placed on bottles containing 1/2 MS liquid medium and kept at $4^{\circ} \mathrm{C}$ for $3 \mathrm{~d}$, and then germinated in growth chambers at $22^{\circ} \mathrm{C}$ with continuous shake $(80 \mathrm{rpm})$ in the light (approximately $50 \mu \mathrm{mol} / \mathrm{m}^{2} / \mathrm{s}$ ). Six-day-old seedlings were transferred to bottle containing $1 / 2 \times \mathrm{MS}$ medium with or without addition of the fungal toxins, cAMP, DDA, and/or FK as indicated in the text or the figures, and kept under the same growth conditions. The seedlings were collected at different time points, and then immediately frozen in liquid nitrogen and stored at $-80^{\circ} \mathrm{C}$ before SA extraction. SA in the treated seedlings was extracted as described previously [33]. The ethanol extracts were spotted onto silica gel $\left(20 \mathrm{~cm} \times 20 \mathrm{~cm}, \mathrm{GF}_{254}\right)$ and developed in the mixed solvent of toluene:dioxane:acetic acid $(90: 25: 4, \mathrm{v} / \mathrm{v} / \mathrm{v})$ for purification of SA as described previously [34]. The purified SA samples were dissolved in $200 \mu \mathrm{l}$ methanol and $15 \mu \mathrm{l}$ was used for HPLC analysis (Waters Corp., MA, USA) with a spectroflurescence detector (Waters 474, excitation wavelength $=$ $310 \mathrm{~nm}$, emission wavelength $=415 \mathrm{~nm}$ ). The mobile phase solvent was a mixture of methanol and $0.025 \%(\mathrm{v} / \mathrm{v}) \mathrm{H}_{3} \mathrm{PO}_{4}$ at a ratio of 55:45 $(\mathrm{v} / \mathrm{v})$. The SA contents were calculated by comparing the peak area of a known amount of SA in methanol. Recovery rate for SA was between $30 \%$ and $50 \%$.

\section{Determination of cyclic AMP content}

Six-day-old hydroponically growing seedlings were transferred to the bottle containing $1 / 2 \times$ MS medium with or without addition of the toxins, and kept in a growth chamber at $22^{\circ} \mathrm{C}$ with continuous shake $\left(80 \mathrm{rpm}\right.$ ) in the light (approximately $50 \mu \mathrm{mol} / \mathrm{m}^{2} / \mathrm{s}$ ). The seed- 
lings were collected at different time points and washed with distilled water 5 times, and then immediately frozen in liquid nitrogen and kept at $-80^{\circ} \mathrm{C}$ until cAMP extraction. For cAMP extraction, the treated seedlings were grounded in liquid nitrogen and homogenized into $3 \mathrm{ml}$ of $1 \mathrm{M} \mathrm{HClO}_{4}$, and followed by centrifugation at 12,000 g for $10 \mathrm{~min}$ to separate the protein crystals from the acid soluble cAMP. The supernatant was mixed with $1 \mathrm{M} \mathrm{KOH}$ solution and lyophilized, and the extract was stored at $-20^{\circ} \mathrm{C}$. The cAMP contents in the extracted samples were assayed using the cAMP-EIA kit (RPN225; Amersham-Pharmacia Biotech, Piscataway, NJ, USA). To increase the sensitivity of the assay, the samples were acetylated following protocols provided with the cAMP-EIA kit. The cAMP standard solutions were prepared ranging from 0.04 to $2.56 \mathrm{pmol} / \mathrm{ml}$ using the standard solutions of cAMP provided in the kit. The cAMP contents were calculated by comparing the standard curve and shown in pmol of cAMP per gram fresh weight.

\section{RNA isolation and hybridization}

Six-day-old plants were grown in $1 / 2$ MS medium with or without addition of the toxins and/or cAMP (or 8-Br-cAMP) as indicated in the text or the figures. The plant samples were collected at different time points after the treatments and kept frozen in liquid nitrogen. Total RNA was extracted using the Trizol Regent (Invitrogen Life Technologies, Carlsbad, CA, USA). Fifteen microgram of total RNA were separated by electrophoresis through $1.2 \%(\mathrm{w} / \mathrm{v})$ formaldehyde-agarose gels and blotted onto a nylon membrane (Hybond$\mathrm{N}^{+}$; Amersham-Pharmacia Biotech, Piscataway, NJ, USA) by capillary transfer. Ethidium bromide was included in the sample-loading buffer at a concentration of $40 \mathrm{mg} / 1$, which allowed photography under UV light after electrophoresis to confirm equal sample loading. The probes for the detection of $P R 1$ transcripts were PCR-amplified with primers of PR1F (5'-ACG TCC AGT CTT CGG CAT CC-3') and PR1R (5'-GAG CTT AAA AAC CCT TCC AG-3'). The genespecific probes were labeled with ${ }^{32} \mathrm{P}$ dCTP (NEN, Boston, MA, USA) using the Rediprime ${ }^{\mathrm{TM}}$ II labeling kit (RPN1633, AmershamPhamacia Biotech, Buckinghamshire, UK) according to manufacture's instructions.

\section{Chemicals}

All chemicals were obtained from Sigma (St Louis, Missouri, USA) unless otherwise indicated. Cyclic AMP, 8-Br-cAMP, SA and DDA were prepared in distilled water. Forskolin was dissolved in dimethyl sulfoxide (DMSO), which gives the final DMSO concentration in the Arabidopsis culture medium at $0.1 \%(\mathrm{w} / \mathrm{v})$. All the stock solutions were kept at $-20^{\circ} \mathrm{C}$ before use.

\section{RESULTS}

\section{Verticillium wilt symptoms in Arabidopsis plants treated with pathogen inoculation or toxins}

It had been reported that Vercitillium fungi might infect Arabidopsis plants to give rise characteristic disease symptoms $[6,7]$. In this study, we first analyzed the susceptibility of Arabidopsis thaliana (ecotype Columbia) to $V$. dahliae strain V229. As shown in Fig. 1A, the inoculated plants showed typical disease symptoms (wilt, chlorosis) after one week infection. Leaf tissues near the acupunctured spots began to be desiccated $1 \mathrm{~d}$ after the injection of the extracted fungal toxins (data not shown). Four days after injection the tissues near the needle holes of the leaves appeared to become necrosis (Fig.1B). The symptoms induced by either fungi inoculation or toxins injection are very similar to that observed on cotton plants (Gossypium hirsutum) (data not shown). Furthermore, susceptibility of Arabidopsis to the isolated toxins was tested on seedlings growing on MS medium plates containing toxins. We observed dose-dependent symptoms within toxin concentrations of $10 \mu \mathrm{g} / \mathrm{ml}$ to $50 \mu \mathrm{g} / \mathrm{ml}$ (Fig. 1C). Root growth was completely inhibited in the presence of toxins at all tested concentrations, suggesting that Arabidopsis roots are highly sensitive to toxins. When the concentration was higher than $30 \mu \mathrm{g} / \mathrm{ml}$, toxin-induced cotyledon chlorosis was observed after 4 days' growth in toxin-containing medium (Fig. 1C). Thus, Arabidopsis can be used as a model plant to study plant-microb interacting mechanism between $V$. dahliae and higher plants. A concentration of $40 \mu \mathrm{g} / \mathrm{ml}$ toxins was used as the standard "Toxin-Treatment" in all of the following experiments.

\section{Both exogenous cAMP and salicylic acid significantly increase resistance of Arabidopsis seedlings to Verti- cillium toxins}

It has been reported that exogenously supplied SA can rapidly enter cells and the uptake of SA preceded the establishment of induced plant resistance to pathogen infection [35]. There were also studies suggesting that cyclic AMP might be involved in the hypersensitive response of higher plants to fungal elicitors $[19,20]$. In order to test if cAMP and/or SA are involved in interaction between $V$. dahliae and Arabidopsis plants, we examined the possible role of exogenous cAMP and SA on Arabidopsis resistance to the fungal toxins. Either $10 \mathrm{nM} \mathrm{SA}$ or $10 \mu \mathrm{M}$ 8-Br-cAMP (a membrane-permeable form of cAMP) was added to Arabidopsis culture medium. As shown in Fig. 1D, leaf chlorosis induced by fungal toxins was significantly reduced after addition of either SA or 8-Br-cAMP. However, exogenous 8-Br-cAMP did not reduce toxininduced phenotype in SA-deficient Arabidopsis $N a h G$ mutants (Fig. 1E), suggesting that endogenous cAMP may act as an upstream signaling molecule in SA-mediated pathogen defense pathway.

\section{Verticillium toxins elevate endogenous cAMP in Arabidopsis seedlings}

We further hypothesized that $V$. dahliae toxins may induce change in endogenous cAMP level in plants during early stage of toxin treatment. To test this hypothesis, endogenous cyclic AMP was measured in Arabidopsis seedlings using EIA methods as described in Materials and Methods. As shown in Fig. 2, the basal level of endog- 

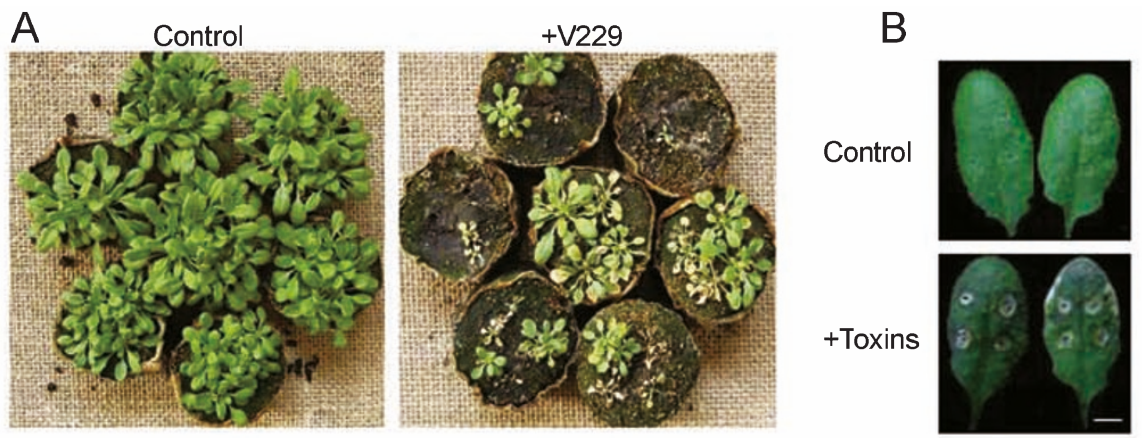

C
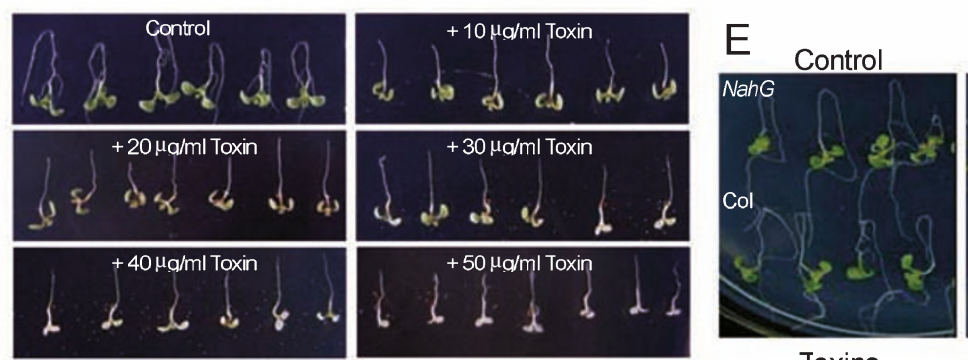

8-Br-CAMP
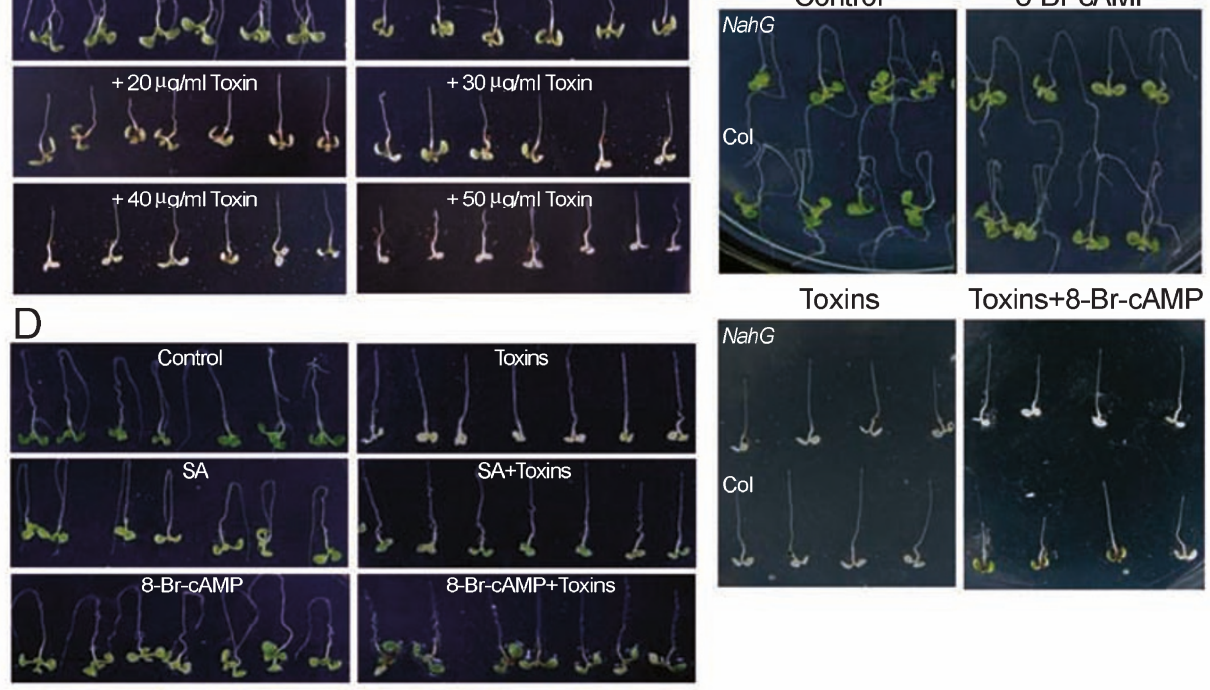

Toxins+8-Br-cAMP
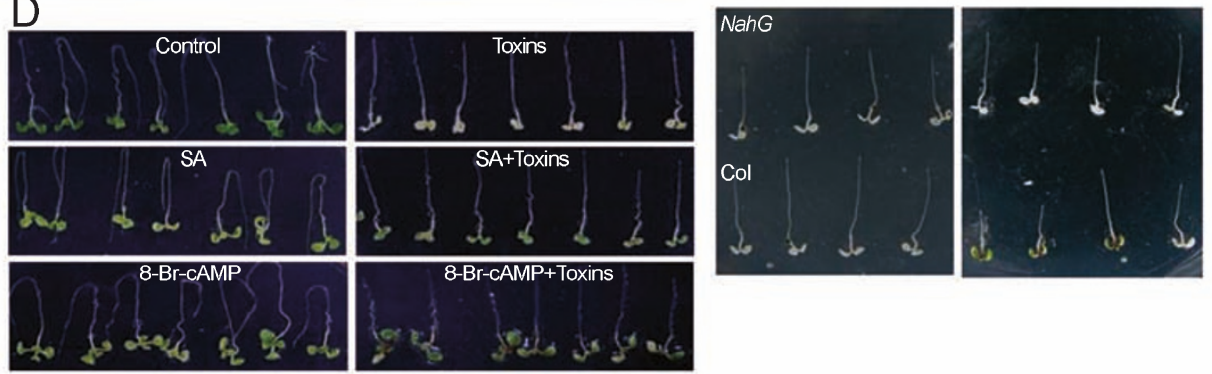

$\mathrm{F}$

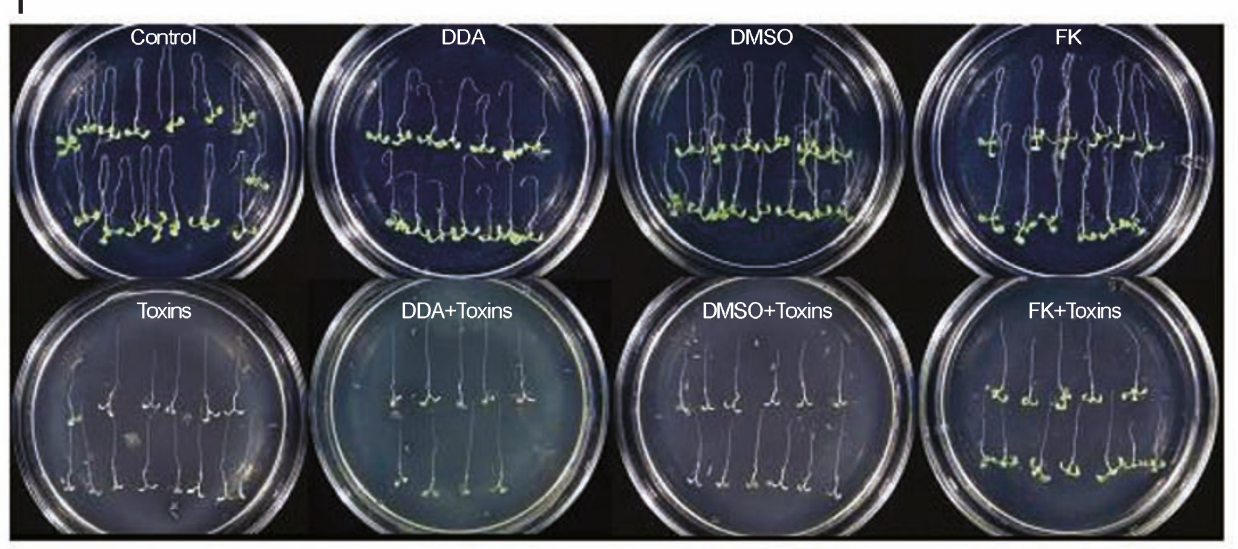

Fig. 1 Verticillium disease symptoms of Arabidopsis plants under various growth conditions. (A) Soil-grown Arabidopsis (ecotype Columbia). Photographs show mock-inoculated (control) and V. dahliae-inoculated (+V229) Arabidopsis. V. dahliae-inoculation induced significant wilt and chlorosis appeared one week after the inoculation. (B) Hypersensitive response of Arabidopsis leaves (ecotype Columbia) injected with $V$. dahliae toxins. The leaves were photographed 4 days after the injection (scale bar, $5 \mathrm{~mm})$. (C) Phenotype of Arabidopsis seedlings grown in the medium containing toxins at different concentrations as indicated. (D) Effects of exogenous SA $(10 \mathrm{nM})$ and 8-Br-cAMP $(10 \mu \mathrm{M})$ on the phenotype of Arabidopsis seedlings in the presence or absence of the toxins. Photographs were taken 4 days after the treatments. (E) Phenotype comparison between wild type (Col) and the NahG transgenic line in the presence or absence of the toxins and exogenous 8-Br-cAMP $(10 \mu \mathrm{M})$. (F) Effects of $100 \mu \mathrm{M}$ DDA (an inhibitor of adenylyl cyclase) and $10 \mu \mathrm{M}$ forskolin (FK, an activator of adenylyl cyclase) on the disease symptoms of Arabidopsis seedlings in the presence or absence of the Verticillium toxins. The addition of $0.1 \%$ (w/v) DMSO alone (the photo of Petri dish labeled with DMSO) was taken as the control (because FK stock solution was made in DMSO and the final concentration of DMSO in the medium was $0.1 \%$ (w/v). 


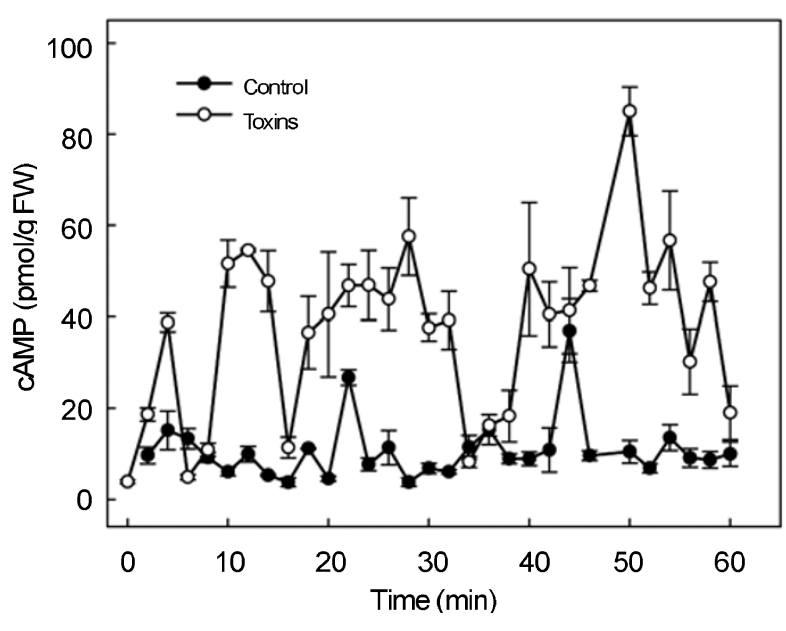

Fig. $2 \mathrm{~V}$. dahliae toxin-induced endogenous cAMP elevation in Arabidopsis seedlings. Cyclic AMP was extracted at different time points after challenged with the toxins and assayed by EIA methods. The experiments were repeated three times and each time point in one experiment had three replicates. The data were presented as mean $\pm \operatorname{SE}(n=3)$.

enous cAMP in Arabidopsis seedlings was averaged at 6 $\mathrm{pmol} / \mathrm{g} \mathrm{FW}$ under the control conditions. A very rapid and dramatic increase of endogenous cAMP concentration was observed after the toxin treatment, and the endogenous cAMP concentration reached to 9-10 folds higher than that of the control after 4 min toxin treatment (Fig. 2). Interestingly, the toxin-induced transient cAMP elevation occurs in an oscillating pattern (Fig. 2) although its biological importance is unknown yet. These results strongly suggest that endogenous cAMP in Arabidopsis plants is involved in plant defense signaling pathway.

\section{Exogenous cAMP- and the toxin-induced SA accumu- lation in Arabidopsis plants}

Salicylic acid (SA) is a known signaling molecule involved in plant defense responses to pathogens (reviewed in $[24,25,27])$. We have shown above in Fig. 1D that exogenous SA significantly increased the disease resistance of Arabidopsis seedlings to Verticillium toxins. Furthermore, the amount of endogenous SA in Arabidopsis seedlings increased dramatically due to the presence of membranepermeable 8-Br-cAMP or the fungal toxins in the culture medium (Fig. 3A). Free SA content in Arabidopsis seedlings began to increase $12 \mathrm{~h}$ after the exposure to $8-\mathrm{Br}$ cAMP, and reached the maximal level at $24 \mathrm{~h}$, and then decreased afterwards (Fig. 3A). Similarly, the toxin treatment induced significant increase of free SA content, which occurs later at $20 \mathrm{~h}$ and reached the maximal level at $48 \mathrm{~h}$ and then decreased afterwards (Fig. 3A). As a control, membrane-impermeable exogenous cAMP did not have any effect on SA accumulation (Fig. 3A). When both the toxins and 8-Br-cAMP were present, the accumulation of free SA occurs first as a small peak at $12 \mathrm{~h}$ after the exposure, followed by a broad and more significant increase between $60 \mathrm{~h}$ and $100 \mathrm{~h}$ after the treatment. The maximum accumulations of free SA in Arabidopsis seedlings upon treatment of toxins or 8-Br-cAMP or both toxins and 8-Br-
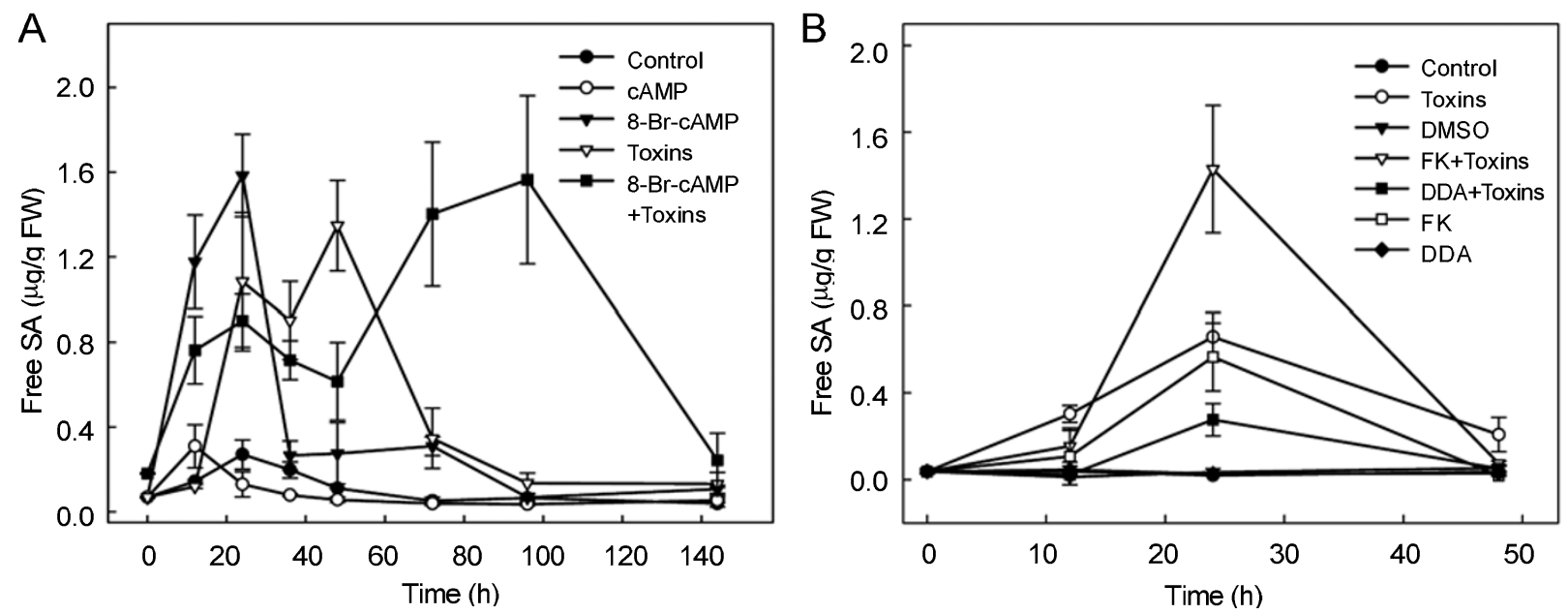

Fig. 3 Effects of the toxins or cAMP on SA production in Arabidopsis seedlings. (A) Time kinetics of exogenous cAMP- or the toxininduced changes in endogenous free SA contents. The toxins and cAMP concentrations were $40 \mu \mathrm{g} / \mathrm{ml}$ and $10 \mu \mathrm{M}$, respectively. (B) Effects of AC (adenylyl cyclase) regulators DDA $(100 \mu \mathrm{M})$ and FK $(10 \mu \mathrm{M})$ on endogenous free SA contents. All experiments were repeated three times and each time point in one experiment had three replicates. The data were presented as mean $\pm \operatorname{SE}(n=3)$. 


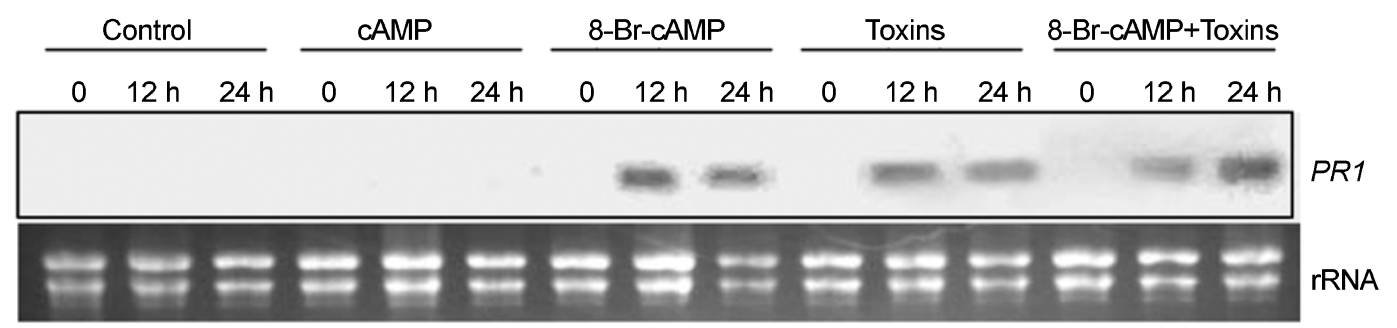

Fig. 4 Verticillium dahliae toxins $(40 \mu \mathrm{g} / \mathrm{ml})$ and exogenous cAMP $(10 \mu \mathrm{M})$ induced increases of $P R 1$ transcription in Arabidopsis plants. Ethidium bromide-stained ribosomal RNA bands (rRNA) in RNA gel blots were used as the loading control.

cAMP were very similar (Fig.3A). Furthermore, modulation of endogenous cAMP by regulating adenylyl cyclase activity also induced changes in SA level in Arabidopsis seedling (Fig. 3B). Addition of forskolin (FK), an adenylyl cyclase activator to promote intracellular cAMP level, significantly induced endogenous SA in Arabidopsis seedlings after $12 \mathrm{~h}$ incubation, and endogenous SA content reached the highest level after $24 \mathrm{~h}$ incubation (Fig. 3B). The FKinduced SA increase was toxins-independent (Fig. 3B). There is addiditive effect on SA elevation when toxin and FK were used together (Fig. 3B). On the otherhand, 2', 5 '-dideoxyadenosine (DDA), an inhibitor of adenylyl cyclase, significantly reduced toxin-induced endogenous SA accumulation (Fig. 3B). Taken together, these results strongly suggest that endogenous cAMP is a functional regulator of SA production in vivo.

\section{Toxin- and exogenous cAMP-induced expression of PRI gene}

It is known that the expression of pathogenesis-related $(P R)$ genes is regulated by SA-mediated signaling pathway (reviewed in [36]). Thus, we analyzed $P R 1$ gene expression in Arabidopsis plants treated with toxins and/or cAMP analogue. As shown in Fig. 4, PR1 expression was undetectable in the absence of the toxins and 8-Br-cAMP, while application of the toxins or 8-Br-cAMP or both significantly induced $P R 1$ expression. However, membraneimpermeable cAMP had no effect on $P R 1$ expression (Fig. 4), suggesting that cAMP does regulate pathogenesis-related genes, most likely via regulating SA level.

Based on above observations, we conclude that endogenous cAMP functions in plant defense pathway against pathogenic fungal infection as a positive regulator via regulation of endogenous SA production or accumulation and subsequently regulates downstream pathogenesis-related gene expression and plant defense responses.

\section{DISCUSSION}

In the present study, we have shown in Arabidopsis

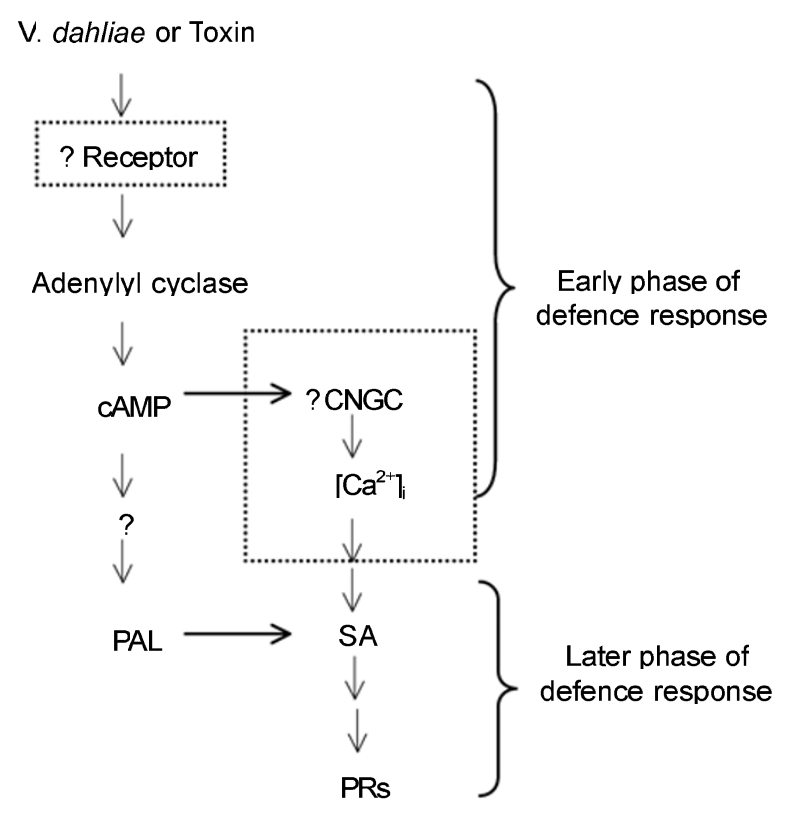

Fig. 5 Proposed working model for cAMP-mediated Arabidopsis defense mechanisms in responses to Verticillium dahliae infection or Verticillium dahliae toxin challenge. The components shown in boxes with dotted lines are hypothetical. $\left[\mathrm{Ca}^{2+}\right]_{i}$, cytosolic $\mathrm{Ca}^{2+}$ concentration; CNGCs, cyclic nucleotide-gated channels; PRs, pathogenesis-related proteins; PAL, phenylalanine ammonia-lyase; SA, salicylic acid.

plants that $V$. dahliae toxins can elevate endogenous cAMP and SA. Introducing of cAMP homologue and SA exogenously can lead to greater disease resistance of Arabidopsis plants to the pathogen infection or the toxin treatment. Endogenous SA increases significantly upon cAMP homologue treatment, thus cAMP is probably a signal upstream of SA in plant defense pathway. PRI transcription responds rapidly to exogenously applied cAMP homologue, probably via cAMP-induced elevation of intracellular SA signal. The $P R 1$ expression reached the maximal level at $24 \mathrm{~h}$ after both exogenous cAMP and toxins applied (Fig. 4), 
which is well correlated with cAMP- and toxin-induced SA elevation as shown in Fig. 3B. Based on these data, we propose a working model for cAMP-mediated signaling pathway for plant early defense responses to pathogenic attacks (Fig. 5). When fungus $V$. dahliae or toxins is present, adenylyl cyclase (AC) is somehow activated, leading to elevation of cytosolic cAMP signals. The linker(s) between pathogens and $\mathrm{AC}$ is however still unknown and a receptor and/or G-protein are probably involved. Cytosolic cAMP may regulate calcium-permeable ion channel, such as CNGCs (cyclic nucleotide-gated channels), to increase cytosolic $\mathrm{Ca}^{2+}$ concentration and subsequently regulate SA synthesis. Alternatively, cAMP may stimulate SA biosynthesis through activating PAL [19], a known key enzyme in SA synthesis, and accumulation of phytoalexin and cell wall phenolic substances. Upon an increase in cytosolic SA concentration, plant defense pathway is activated, such as phytoalexin induction and PR protein expression. Membrane-permeable cAMP analogue, but not membrane-impermeable analogue, is effective in inducing SA accumulation and disease resistance of Arabidopsis plants to the toxins. cAMP is an intracellular second messenger, thus most likely it will target to an intracellular molecule or the cytoplasmic domain of a plasma membrane-localized protein.

Pathogen infection has to be first recognized by plant resistance system and then the interaction between the host and the pathogen will initiate signaling processes to generate second messengers and to trigger subsequent defense responses (reviewed in [24, 25]). The early events including membrane potential changes, ion fluxes, and active oxygen species production occur rapidly in response to pathogen attacks (reviewed in [37]). Later responses of plants to pathogen such as the production of phytoalexins and induction of defense gene expression followed. In the present study, we observed that endogenous cAMP was responding to toxin induction rapidly in an oscillated manner. The toxin-induced rapid change of endogenous cAMP suggests that cAMP may act as an important signaling molecule during the early stage of plant defense responses.

Intracellular concentrations of cAMP reported previously varied in higher plants, ranging from $0.5 \mathrm{pmol} / \mathrm{g} \mathrm{FW}$ to $80 \mathrm{pmol} / \mathrm{g} \mathrm{FW}$ (reviewed in [10]). The difference may result from experimental methods used by different groups. We used cAMP enzymeimmunoassay (EIA) kit for the measurement of the endogenous cAMP concentrations in plant tissues and obtained repeatable results of about $6 \mathrm{pmol} / \mathrm{g}$ FW under the control conditions (Fig. 2). Our results have shown that cAMP in plant cells is usually kept at a very low concentration under normal growth condition and will be increased 10 to 15 -fold in response to stimuli such as a pathogenic fungal attack. Further attention should be paid to the fluctuation changes in cytosolic cAMP we have observed after the toxin treatment (Fig. 2), although the mechanism behind is unknown.

It is known that plant cells possess cyclic nucleotidegated channels to transport ions such as sodium, potassium or calcium [38]. Environmental stimuli are potent inducers of cytosolic $\mathrm{Ca}^{2+}$ spikes $\left(\left[\mathrm{Ca}^{2+}\right]_{\mathrm{i}}\right)$ with specific $\mathrm{Ca}^{2+}$ signatures of different amplitudes, kinetics and spatial distributions. The stimulus-induced changes in $\left[\mathrm{Ca}^{2+}\right]_{\mathrm{i}}$ could be transient, sustained, or oscillatory. There are several studies about the involvement of cAMP or cGMP in elevation of $\left[\mathrm{Ca}^{2+}\right]_{i}[18,39]$. It is reasonable to propose the existence of a tight correlation between cytosolic cAMP and $\mathrm{Ca}^{2+}$ in signal transduction of plant defense responses. Members of CNGC family of ion transporters may be good candidates for down-stream targets and effectors of cyclic nucleotide signals in plants [38], for example in plant pathogen response $[22,23]$.

In conclusion, the results presented in this work strongly suggest that the endogenous cAMP is involved in signal transduction of plant defense responses through regulation of SA production. Further understanding of cAMPmediated plant defense signaling requires identification of upstream components in cAMP synthesis and downstream targets of elevated cytosolic cAMP.

\section{ACKNOWLEDGEMENTS}

We would like to thank Dr. Xin Nian DONG (Department of Botany, Duke University, Durham, North Carolina) for kindly providing Arabidopsis $\mathrm{NahG}$-transgenic plants. We also thank Dr. Ying Zhang LI (College of Biological Sciences, China Agricultural University, Beijing, China) for providing Verticillium dahliae strain V229. The work was supported by the National Science Foundation of China (Grant No. 39930010) and a NSFC Fund for Creative Research Groups (Grant No. 30421002) to Wei Hua WU.

Received, Apr 30, 2005

Revised, July 29, 2005

Accepted, Aug 4, 2005

\section{REFERENCES}

1 Goth RW, Webb RE. Sources and genetics of host resistance in vegetable crops. In: Mace MA, Bell AA, Beckman CH. Eds. Fungal Wilt Diseases of Plants. Academic Press: New York 1981: 377-411.

2 Wilhelm S. Sources and genetics of host resistance in field and fruit crops. In: Mace MA, Bell AA, Beckman CH. Eds. Fungal Wilt Diseases of Plants. Academic Press: New York 1981:30076.

3 Bhat RG, Subbarao KV. Host range specificity in Verticillium 
dahliae. Phytopath 1999; 89:1218-25.

4 Schnathorat WC. Life cycle and epidemiology of Verticillium. In: Mace MA, Bell AA, Beckman CH. Eds. Fungal Wilt Diseases of Plants. Academic Press: New York 1981:81-111.

5 Kawchuk LM, Hachey J, Lynch DR, et al. Tomato Ve disease resistance genes encode cell surface-like receptors. Proc Natl Acad Sci U S A 2001; 98:6511-5.

6 Steventon LA, Okori P, Dixelius C. An investigation of the susceptibility of Arabidopsis thaliana to isolates of two species of Verticillium. J Phytopathol 2001; 149:395-401.

7 Veronese P, Narasimhan ML, Stevenson RA, et al. Identification of a locus controlling Verticillium disease symptom response in Arabidopsis thaliana. Plant J 2003; 35:574-87.

8 Kronstad JW. Virulence and cAMP in smuts, blasts and blights. Trends Plant Sci 1997; 2:193-9.

9 Knogge W. Fungal pathogenicity. Cur Opin Plant Biol 1998; 1: 324-8.

10 Assmann SM. Cyclic AMP as second messenger in higher plants. Plant Physiol 1995; 108:885-9.

11 Bolwell GP. Cyclic AMP the reluctant messenger in plants. Trends Biochem Sci 1995; 20:492-5.

12 Newton RP, Roef L, Witters E, Van Onckelen H. Cyclic nucleotides in higher plants: the enduring paradox. New Phytol 1999; 143:427-55.

13 Trewavas AJ, Rodrigues C, Rato C, Malhó R. Cyclic nucleotides: the current dilemma! Curr Opin Plant Biol 2002; 5:425-9.

14 Moutinho A, Hussey PJ, Trewavas AJ, Malhó R. cAMP acts as a second messenger in pollen tube growth and reorientation. Proc Natl Acad Sci U S A 2001; 98:10481-6.

15 Biermann B, Johnson EM, Feldman LJ. Characterization and distribution of a maize cDNA encoding a peptide similar to the catalytic region of second messenger dependent protein kinases. Plant Physiol 1990; 94:1609-15.

16 Katagiri F, Lam E, Chua NH. Two tobacco DNA binding proteins with homology to the nuclear factor CREB. Nature 1989; 340:727-30.

17 Bolwell GP. A role of phosphorylation in the down-regulation of phenylalanine ammonia lyase in suspension-cultured cells of French bean. Phytochem 1992; 31:4081-6.

18 Kurosaki F, Nishi A. Stimulation of calcium influx and calcium cascade by cyclic AMP in cultured carrot cells. Arch Biochem Biophys 1993; 302:144-51.

19 Cooke CJ, Smith CJ, Walton TJ, Newton RP. Evidence that cyclic AMP is involved in the hypersensitive response of Medicago sativa to a fungal elicitor. Phytochem 1994; 35:899905.

19 Zhao J, Guo Y, Fujita K, Sakai K. Involvement of cAMP signaling in elicitor-induced phytoalexin accumulation in Cupressus lusitanica cell cultures. New Phytol 2003; 161:723-33.

20 Bent A, Kunkel B, Dahlbeck D, et al. RPS2 of Arabidopsis thaliana: a leucine-rich repeat class of plant disease resistance genes. Science, 1994; 265:1856-60.
21 Clough SJ, Fengler KA, Yu IC, et al. The Arabidopsis dnd1 'defense no death' gene encodes a mutated cyclic nucleotide-gated ion channel. Proc Natl Acad Sci U S A 2000; 97:9323-8.

22 Balagué C, Lin B, Alcon C, et al. HLM1 an essential signaling component in the hypersensitive response is a member of the cyclic nucleotide-gated channel ion channel family. Plant Cell 2003; 15:365-79.

23 Durner J, Shah J, Klessig DF. Salicylic acid and disease resistance in plants. Trends Plant Sci 1997; 2:266-74.

24 Smith HB. Signal transduction in systemic acquired resistance. Plant Cell 2000; 12:179-81.

25 Dong X. Genetic dissection of systemic acquired resistance. Curr Opin Plant Biol 2001; 4:309-14.

26 Shah J. The salicylic acid loop in plant defense. Curr Opin Plant Biol 2003; 6:365-71.

27 Gaffney T, Friedrich L, Vernooij B, et al. Requirement of salicylic acid for the induction of systemic acquired resistance. Science 1993; 261:754-6.

28 Bate NJ, Orr JNW, Meromi A, et al. Quantitative relationship between phenylalanine ammonis-lyase levels and phenylpropanoid accumulation in transgenic tobacco identifies a rate-determining step in natural product synthesis. Proc Natl Acad Sci U S A 1994; 91:7608-12.

29 Mauch-Mani B, Slusarenko AJ. Production of salicylic acid precursors is a major function of phenylalanine ammonia-lyase in the resistance of Arabidopsis to Peronospora parasitica. Plant Cell 1996; 8:203-12.

30 Meyer R, Slater V, Dubery I. A phytotoxic protein-lipopolysaccharide complex produced by Verticillium dahliae. Phytochem 1994; 35: 1449-53.

31 Brodford MM. A rapid and sensitive method for the quantitation of microgram quantities of protein utilizing the principle of protein dye binding. Anal Biochem 1976; 72:248-55.

32 Palva TK, Hurtig M, Saindrenan P, Palva ET. Salicylic acid induced resistance to Erwinia carotovora subsp carotovora in tobacco. Mol Plant Microbe Interact 1994; 7:356-63.

33 Rasmussen JB, Hammerschmidt R, Zook MN. Systemic induction of salicylic acid accumulation in cucumber after inoculation with Pseudomonas syringae pv syringae. Plant Physiol 1991; 97:1342-7.

34 Thulke O, Conrath U. Salicylic acid has a dual role in the activation of defense related genes in parsley. Plant J 1998; 14:35-42.

35 Glazebrook J. Genes controlling expression of defense responses in Arabidopsis-2001 status. Curr Opin Plant Biol 2001; 4:301-8.

36 Nürnberger T, Scheel D. Signal transmission in the plant immune response. Trends Plant Sci 2001; 6:372-9.

37 Talke IN, Blaudez D, Maathuis FJM, Sanders, D. CNGCs: prime targets of plant cyclic nucleotide signaling. Trends Plant Sci 2003; 8:286-93.

38 Volotovski ID, Sokolovsky SG, Molchan OV, Knight MR. Second messengers mediate increases in cytosolic calcium in tobacco protoplasts. Plant Physiol 1998; 117:1023-30. 